\title{
PROFESIÓN MAESTRO Y CULTURA ESCOLAR: RELATOS DE EXPERIENCIA ${ }^{1}$
}

\author{
ANDRÉS KLAUS RUNGE-PEÑA \\ Universidad de Antioquia
}

\section{GABRIEL JAIME MURILLO-ARANGO}

Universidad de Antioquia

\section{RESUMEN}

\section{ABSTRACT}

El presente artículo es producto de un diálogo de muchas voces, que aún no culmina, a propósito de los fundamentos teóricos y metodológicos del proyecto de investigación Cultura escolar, profesionalidad pedagógica y trayectos biográfico-profesionales: Un estudio cualitativo en nueve subregiones de Antioquia (Colombia), desarrollado con el auspicio de la Secretaría de Educación para la Cultura de Antioquia durante los años 2017-2018. Del diálogo hacen parte alrededor de dos centenares de maestros rurales, junto con los profesores investigadores de nueve universidades de la región concertados en una apuesta por la investigación educativa asociada a una línea de formación continua de maestros con un enfoque biográfico-narrativo. En la primera fase del proyecto los maestros se aplicaron en la elaboración de narrativas de memoria escolar entre la guerra y la paz, mientras en la segunda fase, todavía en marcha, la atención se centra en los relatos de experiencia de maestros en tiempos de incertidumbre, como también acerca de la cultura escolar.

Palabras claves: Profesión maestro. Saberes de experiencia. Biografización. Cultura escolar.

\section{TEACHING PROFESSION AND SCHOOL CULTURE: EXPERIENCE REPORTS}

This article is the result of an ongoing dialog among many voices, held for the support of the Education and Culture Secretariat of Antioquia, in 2017-1018, regarding the theoretical and methodological

1 Este artículo ha sido escrito al hilo de una discusión a muchas voces sobre los fundamentos teóricos y metodológicos del proyecto de investigación Cultura escolar, profesionalidad pedagógica y trayectos biográficos profesionales: Un estudio cualitativo en nueve subregiones de Antioquia (Colombia), desarrollado en el Centro de Pensamiento Pedagógico de Antioquia (CPP) con el auspicio de la Secretaría de Educación para la Cultura de Antioquia durante los años 2017-2018. En la realización de las sesiones de trabajo participaron numerosas personas, inicialmente, los maestros y maestras de catorce municipios, al año siguiente doblados en número, junto con los profesores investigadores de nueve universidades de la región concertados en una apuesta por la investigación educativa asociada a una línea de formación continua de maestros con un enfoque biográfico-narrativo. 
foundations of the research project named School Culture, Pedagogic Professionalism and Biographic-professional Journeys: a Qualitative Study in Nine Sub-regions of Antioquia (Colombia). Around two hundred rural teachers participate, joined by professors-researchers of nine regional universities. Their efforts concentrate on a proposal for research in education associated to a line of continuous training for schoolteachers, with a biographic-narrative approach. On the first stage, the teachers focused on narrating school memories between war and peace. On the second stage, which is currently developing, the attention is on teachers' storytelling about their experience during times of uncertainties, as well as on school culture.

Keywords: Teaching profession. Experience knowledge. Biographyzing. School culture.

\section{RESUMO PROFISSÃO DOCENTE E CULTURA ESCOLAR: RELATOS DE EXPERIÊNCIAS}

Este artigo é o resultado de um diálogo ainda em desenvolvimento entre muitas vozes, sobre os fundamentos teóricos e metodológicos do projeto de pesquisa Cultura escolar, profissionalismo pedagógico e percorridos biográficos-profissionais: estudo qualitativo em nove sub-regiões da Antioquia (Colômbia). o diálogo é desenvolvido com apoio da Secretaria da Educação e da Cultura da Antioquia, durante os anos 2017-2018, e a participação de aproximadamente duzentos professores rurais, acompanhados por professores-pesquisadores de nove universidades da região. Eles estão concertados em uma aposta pela pesquisa em educação associada a uma linha de formação contínua de professores com foco biográfico-narrativo. Na primeira etapa do projeto, os professores estiveram focados na elaboração de narrativas de memória escolar entre a guerra e a paz. Na segunda etapa, ainda em processo, o foco está nos relatos das experiências dos professores em tempos de incerteza, e na cultura escolar.

Palavras-chave: Profissão docente. Saberes da experiência. Biografização. Cultura escolar.

\section{Profesión maestro en tiempos de incertidumbre}

Abordar el estado de la profesión maestro en la actualidad pasa por reconocer las profundas transformaciones sociales, culturales y políticas desatadas desde las décadas finales del siglo XX con la expansión de la economía capitalista global y el vertiginoso desarrollo de las tecnologías digitales. Un telón de fondo cosido con distorsiones, contradicciones, reta- 
zos, que es nombrado con precisión por Andy Hargreaves (1998, p. 73-116) como la época de "las paradojas posmodernas".

De acuerdo con este autor, la tendencia de la economía mundial a romper las fronteras de los mercados nacionales conlleva no solo cambios drásticos en las esferas de la producción, circulación y consumo que subvierten las dinámicas del capital y el trabajo, sino, además, favorece la conversión de la información y el conocimiento en bienes transables. De este modo se sienten los efectos en los sistemas escolares, forzando la adopción de modelos gerencialistas propios de la empresa privada y sesgando la razón de ser de la escuela hacia la satisfacción de las exigencias del mercado.

Sin embargo, en este marco global se han originado al mismo tiempo tendencias contradictorias, como puede observarse en el desequilibrio instalado entre los poderes locales y el poder de las grandes corporaciones multinacionales, constituyéndose en un detonante de la irrupción de particularismos locales $y$, con ello, de las diferencias étnicas, identitarias y xenófobas en el extremo. Entre tanto, en el campo escolar se instalan la uniformidad de los contenidos de enseñanza, los estándares curriculares, las pruebas de evaluación de aprendizajes y de acreditación institucional, en no pocos casos diseñadas por agencias privadas antes que por profesionales del sector público.

Al compás de este movimiento toma cuerpo la crisis de los metarrelatos (LYOTARD, 1989) que presidieron las gestas de invención de las naciones en la ola de las revoluciones burguesas del siglo XIX, afianzadas a través de las guerras de posiciones en territorios ocupados que se prolongan hasta nuestros días. Una crisis que toca también a los sistemas ideológicos transhistóricos, de los cuales se desconfia por su vocación totalitaria, viéndose empujados a rivalizar con los pequeños relatos que expre- san las expectativas más cercanas a las comunidades locales y grupos minoritarios que conforman la mayoría de los olvidados de la historia. Mientras tanto en el escenario escolar, la crisis de las grandes narrativas pone sobre el tapete la incógnita referida al presunto agotamiento del modelo de proyecto común civilizatorio encarnado en la escuela republicana, confrontada con un mundo en el que cada vez más se resalta la pluralidad de formas de vida con sus particulares visiones de mundo.

A la lista de paradojas se suma la compresión del tiempo y el espacio, un efecto abonado al salto en las tecnologías de información y comunicación, que trae consigo "el síndrome de la impaciencia" (BAUMAN, 2008, p. 21). Para este autor, en efecto, este es uno de los retos sobresalientes de la educación en la "modernidad líquida" que ve en el paso del tiempo, la espera y la lentitud, amenazas latentes de la eficacia y la productividad, en tanto la instantaneidad, el mayor número de actividades en el menor intervalo de tiempo, así como el acceso ilimitado a los espacios, son consideradas condiciones indispensables del estilo de vida del sujeto posmoderno. Un sujeto embargado, por lo demás, de un ideal de autorrealización personal y proclive a degenerar en autoindulgencia, autoexplotación y aislamiento narcisista, complementado con una precaria sensibilidad social y menguada participación en proyectos colectivos.

En medio de las paradojas del mundo actual, la generación nacida antes de los años setentas del siglo pasado ocupa la posición de actor y testigo de primera mano de los cambios radicales en la economía y la sociedad que afectan los procesos de enseñanza, aprendizaje, convivencia y formación de los sujetos. Asistimos, en efecto, a un cambio acelerado de la condición biográfica en un mundo donde convergen otros modos de hacer la experiencia en el mundo, lo cual justifica la necesidad 
de adaptar los contenidos de transmisión y de socialización en la llamada sociedad biográfica característica de esta etapa de modernidad avanzada.

Esto tiene que ver conque hoy en día se extiende una forma social de descripción de sí y de dar cuenta de sí mismo, a partir de la cual el individuo ya no simplemente aparece adscrito a un estatus social determinado sino más bien modela "su vida", "su trayecto vital", su "trayecto biográfico", al hilo de un proceso que se representa como un tempo-biográfico, es decir, una vida que tira de los hilos de una trama urdida en una línea de tiempo. El individuo queda confrontado con la sociedad de una manera biográfica, es decir, desde temprano se ve abocado a configurar su propia vida, a hacer su propia biografía, en lo que podemos denominar un imperativo biográfico. En este sentido, la formación de sí y del mundo tienen lugar fundamentalmente como un proceso durante toda la vida que implica un trabajo biográfico, esto es, de biografización de la experiencia (DELORY-MOMBERGER, 2009, 2014).

Beck y Beck-Gernsheim analizaron la emergencia del individualismo institucionalizado precisamente como un rasgo distintivo de las "sociedades de riesgo", en las que este tiene lugar no solamente en el mundo económico, sino también en las cada vez más vulnerables condiciones de la vida laboral, es decir, en la ampliación de la precarización en todos los órdenes, y de la cual no escapa el oficio docente catalogado como un oficio precario en situación de crisis en el mundo entero. El individuo como institución en las sociedades de hoy es definido así por este autor:

"Para decirlo en pocas palabras, la individualización está convirtiéndose en la estructura social de la segunda sociedad moderna propiamente tal. El individualismo institucionalizado ya no alude a los sistemas autorreproductores lineales de Talcott Parsons; alude a la paradoja de una "estructura individualizadora" como proceso en curso no lineal, abierto y sumamente ambivalente. Está relacionado con el declive de las narrativas de una sociabilidad dada. Es decir, que están tocando a su fin los colectivismos teóricos de la sociología" (BECK y BECK-GERNSHEIM, p. 30).

La auto realización individual asumida como una institución central en el marco de las relaciones sociales de la vida contemporánea, es elevada a la categoría de un imperativo según el cual somos prisioneros de una combinación de nuevas coacciones, controles y prescripciones sociales, tejiendo una red en la que cada quien debe asumir los riesgos de su propia existencia y sortear por sí solo los obstáculos o fracasos con los cuales lidiar en la vida pública. La paradoja que encierra dicha relación entre "el imperativo biográfico" con un fenómeno acaso imperceptible, engañoso, de recorte de las libertades individuales y aumento de los controles sobre los ciudadanos ejercido por fuerzas oscuras -y estas sí, libres del control-, como parte de un proceso social de "destradicionalización", se expresa patéticamente en "la biografía de la crisis":

La biografia normal se convierte, así, en "biografía electiva", en "biografia reflexiva", en "biografía hágalo usted mismo". Esto no sucede necesariamente por elección ni se salda necesariamente con el éxito. La "biografia hágalo usted mismo" es siempre una "biografia de riesgo", por no decir incluso una "biografía de la cuerda floja", una situación de peligro permanente (en parte abierta y en parte oculta)" (BECK y BECK-GERNSHEIM, p. 40).

\section{VIDAS DE PROFESORES: UNA SINOPSIS HISTÓRICA}

\section{El pensamiento del profesor}

Desde la segunda mitad del siglo XX se han configurado distintas líneas en el campo de las investigaciones contemporáneas sobre la persona y el estatuto profesional del profesor. Ellas 
dibujan una trayectoria cuyo punto de partida está marcado por el interés en el "pensamiento del profesor", en boga durante los años setentas del siglo pasado que, incluso a pesar de la amplia variedad de enfoques, metodologías y objetivos, pretendía cotejar los avances en las ciencias cognitivas con los parámetros establecidos en la metodología experimental heredada de la psicología del condicionamiento operante de Skinner y otros. Simultáneamente con la crítica a la teoría de la reproducción social y cultural, defendida por las versiones ortodoxas del marxismo, se ponía el ojo en las propias creencias y teorías que respaldan la acción del profesor en el aula.

Gracias al paradigma del pensamiento del profesor se abrió la puerta al estudio de los afanes en la vida cotidiana de las escuelas, de las creencias y sentimientos de profesores y alumnos, la estructura de una clase, la interacción en el aula, en suma, estudios sobre la experiencia escolar propiamente dicha (JACKSON, 1999, 2002). Entre estos destacan las teorías implícitas sobre la enseñanza y los profesores, que dieron lugar a un abanico de sinopsis y esquemas de evolución histórica de las ideas pedagógicas con resultados desiguales en sus formas de apropiación en los discursos institucionales, toda vez que con frecuencia se hizo uso de ellas para diseñar taxonomías simplificadoras de "modelos pedagógicos" (FLÓREZ, 1994, p. 161-174).

Con la crítica al modelo conductista de enseñanza centrado en los fenómenos exteriores y observables, ejerció cierta influencia una tendencia que abocó la formulación de teorías lógicas de la educación soportadas en una idea del maestro como pensador o intelectual reflexivo, opuesta a la del maestro como un autómata o programador. Pero no tardaría en descubrirse el callejón sin salida que esperaba tras "la búsqueda del Santo Grial de la enseñanza". Por este camino, en efecto, las argumentaciones formales empañan la red de significados que se tejen entre los sujetos en el trayecto de formación, del mismo modo que concentrarse en la descripción formal de lo que pasa por la cabeza de los profesores supone un divorcio de las prácticas sociales en las que se encuentran inmersos.

De la persistencia en modelar estructuras lógicas solo puede esperarse la quimera de contar con un programa prescriptivo que haga creer que podemos mejorar la enseñanza simplemente haciendo que los docentes piensen de la manera correcta. En consecuencia, se diseñan instructivos o modelos que identifican el acto de enseñanza como un conjunto de rasgos estructurales, ajeno a todo tipo de variaciones y matices, haciendo ver "el compromiso de la docencia como si se produjera dentro de una cápsula del tiempo, como si el acto de enseñar no tuviera ni historia ni futuro" (McEWAN, 2005, p. 244).

Una opción diferente halla en las narrativas un medio de superación de la dicotomía existente entre la filosofía esencialista de la educación y los estudios empíricos, con el propósito de lograr un nuevo objetivo: "contar historias acerca de la docencia, con la esperanza de que al decir algo nuevo aprenderemos a enseñar mejor" (McEWAN, 2005, p. 249).

\section{El conocimiento práctico del profesor}

Más adelante, la atención se centró en el conocimiento práctico de los profesores que sirvió de plataforma de lanzamiento de una imagen del profesor crítico-reflexivo. Desde luego, dicha denominación genérica contiene también sus variantes: la del profesor-investigador de Stenhouse, la del profesor reflexivo-reconstructivo de Zeichner, la del profesor como intelectual de Henri Giroux y la pedagogía crítica. A todas ellas les une el rechazo a una inter- 
pretación excluyente del profesor bien sea en términos de las ciencias cognitivas o bien en relación con las funciones de transmisión cultural, afirmando, por el contrario, el carácter indisociable del pensamiento y la acción, del conocimiento y la sociabilidad.

Pérez y Gimeno (1988, p. 48-53) resumen los rasgos característicos del enfoque sobre el pensamiento práctico de los profesores en una curva de evolución desde una orientación psicologista a una orientación sociológica, y comprende los postulados del constructivismo, las perspectivas fenomenológico-cualitativa y ecológico-naturalista, la concepción de Stenhouse acerca de la enseñanza entendida como un arte, la índole subjetiva del aprendizaje, la conversación reflexiva inherente a la función del profesor, los métodos de la investigación cualitativa, el replanteamiento de las relaciones entre la teoría y la práctica traducido en un enfoque de investigación-acción.

Siguiendo la estela de las indagaciones basadas en visiones críticas sobre el currículo, en Gran Bretaña se desarrolló una tendencia caracterizada por su concepción de los profesores como investigadores, junto con la divulgación de la metodología de investigación-acción (ELLIOTT, 1990; STENHOUSE, 1981, 1985). Esta alternó en su momento con la perspectiva del profesional reflexivo (SCHÖN, 1982), la cual sirvió de pivote multiplicador a la idea de la enseñanza reflexiva (ZEICHNER, 1993), en buena medida procedente de la obra de Dewey, quien definía la acción reflexiva en cuanto implica una apertura intelectual y una actitud de responsabilidad.

La perspectiva reconstruccionista, por su parte, se desarrolla a la luz de la teoría crítica y la investigación-acción, más abierta al diálogo con las ciencias sociales en general, cultivando una mirada crítica sobre la realidad social acompañada de la convicción en el axioma marxista, de acuerdo al cual, la tarea del filó- sofo consiste no solo en interpretar el mundo sino que es necesario transformarlo.

Con Elbaz (1983) se introduce el análisis multidimensional de la actividad docente, probado en el estudio de caso de la profesora Sarah, en el que se distinguen cinco campos de observación, a saber: el de sí misma, el del ambiente pedagógico, el del saber por enseñar, el del currículo y el de la enseñanza. Con base en los datos recogidos mediante la observación en el aula y las entrevistas, Elbaz compuso una matriz que permite identificar las líneas fuerza del accionar práctico de los profesores: situacional, personal, social, experiencial y teórica.

Un hito fundamental en la sucesión de estudios sobre las prácticas de los profesores lo marca "un programa de investigación en dos partes" lanzado por Connelly y Clandinin (1995), que se hace explícito ya en el título del artículo "Relatos de experiencia e investigación narrativa". Es así como la primera parte se propone "escuchar atentamente a los profesores y a otras personas dispuestas a aprender y a los relatos de sus vidas tanto dentro como fuera de clase"; y la segunda parte consiste en el relato mismo de los profesores como investigadores. De este modo, tanto a lo largo del proceso como en sus resultados, "nuestro propio trabajo, entonces, se convierte en un trabajo que consiste en aprender a contar y a vivir un nuevo relato de investigación en la enseñanza y en el aprendizaje que esté construido de forma colaborativa" (CONNELLY y CLANDININ, 1995, p. 51).

\section{Socialización profesional docente}

Otra perspectiva de análisis sobre el tema en cuestión, que ciertamente roza en algunos aspectos con la del pensamiento de los profesores, ha sido la de la socialización profesional, entendida como el proceso mediante el cual los individuos se incorporan a la profesión de 
enseñar y van ganando la experiencia suficiente para el desempeño de funciones cada vez más complejas en su ejercicio profesional.

El tema de la socialización ha sido patrimonio de las teorías funcionalistas desde Durkheim hasta el presente, cuando son aplicadas a la materia específica de la profesionalidad docente acotando el ojo analítico en los antecedentes familiares, el trayecto de formación, los grupos de pares, la experiencia escolar, las prácticas tempranas en la enseñanza. Pero hace rato también ellas se han visto acompañadas de variantes que pretenden romper con el esquematismo y estabilidad de los modelos estructural-funcionalistas originales. En efecto, a estos se opone un paradigma interpretativo que abarca distintas corrientes, tales como el interaccionismo simbólico, la fenomenología, la etnometodología, la etnografia, que indagan por las experiencias subjetivas en el proceso de construcción social.

La célebre escuela de Chicago resplandece a lo largo de dos períodos separados por la segunda guerra mundial, en los estudios que indagan por la interacción en las escuelas y la vida profesional de los maestros. La historia comienza con un clásico temprano de la sociología de la educación y de la familia, The Sociology of Teaching, publicada en1932 por Willard Waller, que anticipa, en cierto modo, una mirada etnográfica al situar la escuela en un haz de relaciones dada su naturaleza como institución social, a la vez que cuestiona la falta de autonomía de los profesores en la toma de decisiones y la realización creativa de las prácticas en el aula.

El camino de Chicago conduce también a la obra de Howard Becker, una que resalta unos pocos conceptos en un horizonte de interpretación del sentido que los sujetos conceden a las acciones en que participan con otros en la vida cotidiana, expresados en múltiples y variados "estudios de caso" que es una de las marcas distintivas de la casa. Estos se refieren a estudios exhaustivos de situaciones particulares, instituciones, acontecimientos, subculturas. Además de su célebre estudio de caso, Boys in White de 1961, sobre los estudiantes de medicina conocidos con el nombre de internos, Becker ya venía estudiando desde la presentación de su tesis doctoral una década atrás los problemas en la carrera de los maestros de las escuelas públicas. Otros estudios de caso de los que se ha ocupado se refieren al tema de las bases sociales determinantes en el consumo de drogas o de cómo hacerse un fumador de marihuana, hasta completar una serie de trabajos en los que puso a prueba la teoría del etiquetado, que es la piedra de toque de una "sociología de la desviación" o de los outsiders, ya fuesen músicos de jazz, artistas, estudiantes internos o maestros de escuela (BECKER, 2009, 2016a, 2016b).

Al cabo de medio siglo de trabajos de la Escuela de Chicago, Dan Lortie renueva una vez más el enfoque y sus resultados en Schoolteacher, aparecido en 1975, basado en las entrevistas en profundidad realizadas a cerca de un centenar de maestros de la periferia de la ciudad de Boston en Estados Unidos, con base en una variedad de temas que comprenden desde el ingreso en la carrera docente, las relaciones con los otros (alumnos, colegas o padres de familia), la distribución horaria en un día en las aulas, los motivos y niveles de satisfacción en la obtención de logros. Estos últimos merecen toda su atención de psicólogo social más que como sociólogo, dadas las diferencias respecto a otras profesiones más conformes con las recompensas económicas, en tanto es propio de la cultura profesional docente la satisfacción con las recompensas "síquicas". El maestro de escuela es caracterizado aquí a partir de tres líneas fuerza o sentimientos predominantes: el presentismo, según el cual el interés se centra en el tiempo corto o la inmediatez; el 
conservadurismo, dado el interés concentrado en la pequeña escala más que en el conjunto del sistema escolar; y el individualismo que se expresa en el aislamiento o la soledad de los profesores.

La ponderación del legado de Lortie en el campo de la investigación sobre los profesores es resumida por Andy Hargreaves (2009) en tres órdenes: en el orden intelectual relieva el valor del trabajo docente en relación con el cambio educativo, como se manifiesta en la multiplicación de proyectos de investigación en esta línea; estratégicamente, allanó el camino para el estímulo de una cultura colaborativa como base de comunidades de aprendizaje, opuesta a una colegialidad artificial que apenas solapa a medias la soledad de los profesores; políticamente, sin embargo, su debilidad es la del interaccionismo simbólico en general, pues no logra dar cuenta de una explicación global de las relaciones existentes entre la microfisica de la realidad escolar y el conjunto de la sociedad, al tiempo que la caracterización del conservadurismo es reducida a un "sentimiento" o un "atributo" desligado de toda concepción de la política y los juegos de poder.

En suma, el análisis de las condiciones que influyen en el proceso de socialización desde la formación inicial es considerado un estudio indispensable si se quiere explicar el desempeño profesional de los profesores. Por supuesto, desde esta óptica de la sociología de las profesiones son tenidos en cuenta otros factores de análisis tales como: edad, sexo, raza, clase social, creencias religiosas, títulos académicos, grado del escalafón docente. Además, intervienen factores institucionales del orden de la tradición de colegios y universidades, el proyecto educativo institucional, los recursos presupuestales, la infraestructura. Y entre los factores pedagógicos, cabe mencionar: el ritmo e intensidad de las interacciones profesor-alumno, la flexibilidad curricular, el tiempo y espacio escolar, el plan de estudios, los textos, el equipo docente (CONTRERAS, 1987, JACKSON, 2002).

Pero más importante aún es el influjo de las prácticas de enseñanza en el itinerario de la carrera, a menudo vista por encima incluso de la formación teórica, es sobre ellas que recae la carga de la ruptura y transición de la salida de la universidad al ingreso en el cuerpo docente, de la condición de alumno a la de profesor y, finalmente, de la teoría al hacer y ser sujeto de la experiencia.

\section{Teorías marxistas y de la reproducción en la escuela}

Después de la segunda mitad del siglo XX, entre los círculos académicos e intelectuales de izquierda en Europa hace carrera la visión de la escuela como un aparato ideológico del Estado, inspirada en las lecturas marxistas de Louis Althusser, Bourdieu y Passeron, o en las versiones anticapitalistas más sobresalientes del período. Es insoslayable la influencia de dichas teorías especialmente en los movimientos sindicales del magisterio de América Latina que, contradictoriamente, resistían los embates del Estado por hacer del maestro un mero administrador de un currículo estándar que le es impuesto desde arriba, afirmando, en contravía, la naturaleza política de un trabajo que encarna la identidad profesional del profesor como intelectual y como un sujeto productor de saber pedagógico.

La figura quizás más representativa de la teoría de la reproducción social y cultural ha sido la de la caja negra, que permite ver un sistema escolar encargado de perpetuar las desigualdades sociales junto con la reproducción de la ideología de las clases dominantes en el sistema capitalista. En su versión radical, Bourdieu expone una analogía entre la liturgia 
católica y la "liturgia de una clase", dado el hecho de que en ambos casos la comunicación eventual que pueda tener lugar entre los interlocutores les es ajena, toda vez que depende solo del reconocimiento de la autoridad de los emisores, el cura o el profesor, a condición de que estos no hablen por cuenta propia sino como portavoces de un discurso por persona interpuesta. En pocas palabras, tanto el cura como el maestro carecen de una voz propia, “y que nunca se autoricen a definir por sí mismos lo que hay que decir y lo que no hay que decir" (BOURDIEU, 1996, p. 30).

A este lado del Atlántico, se consolidó una vertiente crítica del marxismo, quizás más sensible a otras disciplinas que contribuyen igual a la comprensión de las relaciones existentes entre la economía, la cultura y la educación bajo el sistema moderno capitalista. Este es el caso de Peter McLaren, quien deslumbró tempranamente con la incorporación de perspectivas etnográficas y sociológicas en un marco conceptual marxista para el análisis de "la escuela como un peformance ritual" (MCLAREN, 2005, McLAREN, 1995). También Michael Apple, renombrado dirigente sindical de maestros en Estados Unidos, quien se ocupa del análisis de los textos escolares en el circuito económico, de las condiciones sociales objetivas que determinan la evolución del currículo, de los temas de género, raza y desigualdad en el acceso escolar, en fin, de la profesión docente basado en la llamada ideología del profesionalismo. A través de un sinnúmero de artículos y libros alude a la intensificación del trabajo docente, con consecuencias severas en una suerte de agotamiento laboral o en el incremento del stress de los profesores. Una postura profesional crítica habría de actuar como una barrera frente a dicho proceso de proletarización o de precarización laboral, indisolublemente ligada a la resistencia gremial frente al Estado capitalista. Junto a los citados, Henri Giroux (1990) relieva la idea del profesor como intelectual en un horizonte emancipador de la pedagogía crítica que, por lo demás, ha ensalzado la figura de Paulo Freire.

\section{Cultura escolar y saberes de experiencia}

Hace ya quince años uno de nosotros planteaba una aproximación al estudio de la cultura escolar (MURILLO, 2002) a partir de las experiencias compartidas en diversos proyectos de formación y escritura de vida de maestros, los cuales resaltan el tema de las condiciones de la profesionalidad docente en medio de las transformaciones que sacuden el mundo del trabajo y la educación durante el período de cambio de siglo. Un tema íntimamente vinculado con la incorporación en el currículo de formación de maestros de esta problemática sobre la experiencia singular que es "ir a la escuela", dejando abierta la puerta a un enfoque interdisciplinario que diera cabida a la sociología crítica de la educación, la etnografía escolar, la antropología histórica-pedagógica.

Para lograr el propósito señalado se propuso aguzar "la mirada epistémica" (EISNER, 1998), atenta a captar hasta el más sutil de los detalles, las cosas triviales presentes en los afanes cotidianos, la distribución del tiempo y las materias, los espacios, los muebles y útiles. El conjunto de actividades gestadas por la articulación de dichos factores constituye precisamente "el trabajo pedagógico" -según denominación de Elsie Rockwell (2018, p. 503), en cuya superficie bien puede leerse el ritmo de los cambios y continuidades a lo largo de un proceso que trasciende la corta duración.

El enfoque metodológico suponía entonces la recusación simultánea, por un lado, del encantamiento de la sociología funcionalista en su adhesión a las normas integradoras y de cohesión social como prenda de garantía de 
una educación propulsora de movilidad social $y$, por otro, de las aporías de la sociología crítica marxista que establece a priori la existencia de una caja negra reproductora de las desigualdades e ideologías dominantes. En lugar de ello buscaba adscribirse a un horizonte de comprensión de la naturaleza de la educación situado más allá de estrategias de inculcación, en la medida en que se concede a los distintos actores participantes un rol como sujetos creadores, no meramente como receptores pasivos, comprometidos incluso más o menos autónomamente en un trabajo sobre sí mismos. Desde esta perspectiva destaca el significado liminar que posee la experiencia escolar antes que el rol o la función de las posiciones en la estructura social (DUBET y MARTUCCELLI, 1998, p. 14).

De nuevo, hoy en día, estamos frente al tema de la experiencia, como si fuese ineludible el espectro de Walter Benjamin en su reflexión ya clásica sobre narrativa y pobreza de experiencia. Benjamin sentó las bases del pensar acerca de las transformaciones del modo como son transmitidas las experiencias en la modernidad, ya no de la boca al oído, a la manera de los consejos impartidos por los sabios ancianos o los abuelos a sus nietos, sino que la experiencia misma se encuentra cautiva de los sistemas de información. En la historia moderna es esta una mutación decisiva que se hace hegemónica puntualmente después de la segunda década del siglo XX, acompañada de la invención de la radio, la popularidad del cine, la multiplicación de la prensa diaria, hasta llegar al imperio de los medios masivos de comunicación primeramente impresos, luego audiovisuales y digitales en el día de hoy.

La experiencia ejerce una función determinante en el cuadro de los oficios que tienen como línea de acción las relaciones con los otros. Entre los más destacados en el espacio público se cuentan los de la salud, la educa- ción y el trabajo social, que poseen en común precisamente la acción sobre y con otras personas con base en una competencia profesional para sanar, orientar, enseñar, educar, cuidar o acompañar, en tanto es demandada por los sujetos receptores o quienes los representan. Son profesiones en las que cobran todo su espesor los saberes de experiencia, portadores de los saberes, medios y mediaciones que hacen posible los intercambios con otros sujetos en una situación dada de instrucción, de formación o enseñanza.

Solo en la experiencia se adquieren los conocimientos y habilidades de hacer algo bien, con plena conciencia justamente de lo que se hace, para lo cual ha debido existir una preparación previa con compromiso y vocación de acuerdo a ciertos principios universales. De modo que el hacer bien del oficio no reside solamente en un saber hacer, pues "la legitimidad de los profesionales no es estrictamente técnica o instrumental, sino que también se debe a los valores con los que se identifica, en mayor o menor medida, a los profesionales" (DUBET, 2006, p. 42).

Desde esta perspectiva, entendemos que el desarrollo de las profesiones pedagógicas corre parejo con el desarrollo de las disciplinas científicas, aunque aquellas no delimitan propiamente un espacio para la gestación y realización del conocimiento científico, en tanto hacen énfasis en la acción y en su interacción con alumnos. Así como es propio de la naturaleza de la interacción humana la incertidumbre, la imprevisibilidad, el azar, la praxis profesional docente goza de una autonomía en la toma de decisiones adecuadas para hacer frente a las contingencias de la vida diaria. En la medida, pues, en que la teoría y la praxis son inconmensurables, se requiere de la capacidad de juicio o razonabilidad como manera de mediar entre lo general y lo particular, gracias a un saber profesional que supera los 
límites de saberes específicos -y toma cuerpo en el tacto pedagógico, la phrónesis o sabiduría práctica de los griegos antiguos.

El saber profesional pedagógico, marcado por lo científico y lo práctico, es una forma específica de saber que se desarrolla y se diferencia a partir de la actividad laboral y de la formación profesional, según el cual no se establecen diferencias entre lo verdadero y lo falso, como en el ámbito de la ciencia, sino entre lo adecuado y lo no adecuado. El saber de los profesores resulta del encuentro de saberes y prácticas científicas con las cotidianas, vivenciales y laborales.

Esta perspectiva de análisis desde la experiencia permite indagar por las imágenes que han construido los docentes de sí mismos, en tanto sean considerados o no expertos a la hora de interactuar con los alumnos o, por el contrario, cuando se admite la falta de formación pedagógica.

Nuestro interés actual en volver la mirada sobre la profesionalidad pedagógica abreva en las fuentes precedentes que reivindicaron la experiencia de los sujetos, con la advertencia previa de distinguir entre dos nociones que se superponen erróneamente con frecuencia. La primera se refiere a la cualidad de un arte de decir que ya Kant consideraba como un arte de hacer en el que se reconoce un arte de pensar, de donde Michel de Certeau concluye: "Para decirlo con otras palabras, será un relato. Si el arte de decir es en sí mismo un arte de hacer y un arte de pensar, puede ser a la vez su práctica y su teoría" (2007, p. 87). Es, pues, un movimiento dialéctico que hace posible una acción profesional basada en juicios discrecionales para hacer frente a situaciones de incertidumbre, sin duda una noción más rica y matizada que la hace diferente de aquella comúnmente aceptada según los criterios de un conocimiento especializado, la pertenencia a una comunidad cerrada y un cierto nivel de prestigio social (HARGREAVES, 1998, p. 30).

La segunda noción alude a una profesionalización relacionada con estrategias y tácticas puestas en juego en las políticas de formación profesional de maestros, nutrida de las disciplinas de saber que conforman el campo de las ciencias de educación y legitimadas por las instituciones creadas al efecto.

En este orden de ideas, se justifica la analogía que identifica el oficio de maestro como una artesanía intelectual dada la combinación de conocimientos y formas de hacer, que puede ser aprendida por la observación directa de la actuación del maestro, en tanto los aprendices aprenden al lado de su maestro, no mediante la demostración en abstracto sino por la vía de la experimentación directa en el trabajo aplicado. Por esta vía, Alliaud y Antelo (2009) ponderan las grandezas y miserias de "los gajes del oficio" a partir de cuestionar "el modelo de maestra y la maestra modelo", así como rescatar el valor de la re-creación (o autopoiesis) en situaciones impredecibles, la improvisación y la (auto)reflexión de la tarea de enseñar.

Pero "los gajes del oficio" no se restringen a saberes indeterminados, particulares, precarios, o a meras anécdotas, sino que poseen la capacidad de convertir dichas situaciones ordinarias en algo extraordinario, siendo un pivote para hacer de la experiencia una fuerza en movimiento que impulse el cambio y sirva de base del pensamiento reflexivo e investigativo. Ahondar en los saberes de oficio es una tarea inaplazable en la formación profesional:

Lo propio de los saberes de la experiencia radica en su cualidad de asociar los conocimientos y la práctica, el saber y el hacer. Son saberes que se producen en situación, a medida que se enseña, siendo sus productores o referentes los protagonistas de estas situaciones. Al superar la disociación entre teoría y práctica, entre saberes y haceres, se presentan como un componente esencial para posibilitar la enseñanza, sobre todo en los tiempos que corren, cuando 
ya no es suficiente con saber qué decir y cómo decirlo para decidir qué hacer y cómo hacerlo. (ALLIAUD, 2017, p. 74).

Caben también bajo la denominación saberes de experiencia aquellos saberes que entran a hurtadillas en la escuela, es decir, los saberes extraescolares, los saberes derivados del capital cultural diferenciado que es acumulado en el seno de la familia o en los grupos de pares o en los medios masivos de comunicación, de conformidad con un nivel determinado de procedencia social y de un trayecto escolar singular. Nadie llega virgen a la puerta del aula, como una tabula rasa desprovista de algún grado de conocimiento cultural acumulado sino, por el contrario, se llega con un habitus a cuestas, definido por Pierre Bourdieu (1998) como un sistema duradero de disposiciones, esquemas de percepción, normas interiorizadas, que los sujetos van desarrollando a lo largo de la vida en respuesta a las condiciones objetivas en que se encuentran.

Así pues, los saberes de experiencia aseguran un lugar inamovible en los propósitos de formación continua de profesores, guiados por la consigna de cómo se construye saber pedagógico a través de la experiencia directa en las aulas, y no solamente en los tratados de pedagogía o en los referentes teóricos en boga.

\section{Biografias de experiencia escolar}

Cuando hablamos de saberes de experiencia, en rigor damos cuenta de una biografía, cuyo significado emerge literalmente al ser descompuesta la palabra. Bio: vida (en una acepción diferente a zoé); graphía: huella, signo, marca, señal, por extensión, descripción. Bio-grafía, en sentido etimológico, es descripción de un trayecto de vida. No cesamos de biografiar lo que vivimos, inscribiendo, escribiendo en el curso de nuestra existencia lo que es incorporado en un relato, vamos construyendo si- multáneamente con las experiencias vividas un relato que aspira a una reflexión sobre sí. El trayecto biográfico se estructura con independencia de la forma de expresión que aquel habría de adoptar, sea un texto o una representación visual o un álbum fotográfico o una performance ritual.

Se comprende así que la experiencia está en el corazón mismo de la investigación biográfica en educación, toda vez que los aprendizajes escolares como las vivencias que se han convertido en un capital cultural disponible en el campo de la interacción social, son determinantes en los procesos de formación a lo largo de la vida. En la escuela se adquieren no solo conocimientos académicos sino también estrategias de comportamiento, emociones, sentimientos, formas de razonar y actuar con otros, lo cual permite fundamentar la experiencia como marco y estructura de aprendizaje:

Los documentos biográficos lo testimonian ampliamente: lo que los adultos en formación retienen de la escuela, lo que designan de su tiempo escolar como significativo para sus trayectos formativos son, mucho más que los contenidos del conocimiento, las experiencias relacionales, afectivas, sociales, en las que la escuela ha sido para ellos el campo en que la polaridad emocional ha marcado su relación con el aprendizaje y con el saber (DELORY-MOMBERGER, 2014, p. 707).

En la sociología alemana contemporánea se ha forjado y puesto en acción en la práctica investigativa el influyente concepto biografia de experiencia. Por este se entiende de que no hay biografia sin aprendizaje ni aprendizaje sin biografia, puesto que el aprendizaje no se refiere a la adquisición y apropiación progresiva de saberes o competencias específicas, sino al proceso altamente organizado de reelaboración, vinculación y (trans)formación de los procesos primarios de aprendizaje en una figura biográfica de experiencias, es decir, en 
una especie de "segundo orden" del proceso de aprendizaje.

A partir de su larga experiencia de trabajo con adultos, dichos autores conceden una elevada significación a las biografias de los alumnos, como quiera que los procesos de aprendizaje de hecho están supeditados a la reflexión que ellos hacen sobre su misma experiencia escolar, la que es puesta en el foco de atención de la investigación educativa. De hecho, dado que desde la modernidad en occidente hemos sido ungidos como hijos de la escuela, ello ha conducido irremediablemente a una suerte de naturalización de un fenómeno, una institución y unas prácticas, que no deberían estar exentas de ser explicadas históricamente en sus condiciones de emergencia y modo de funcionamiento.

Se trata, pues, de pensar objetivamente acerca del significado de la experiencia escolar en las historias de vida individuales (tanto de alumnos, como docentes y directivos), no vista solamente como el lugar por antonomasia donde vamos a aprender saberes disciplinares sino también como el lugar donde aprendemos a vivir juntos, aprendemos los rituales de la interacción social, los imponderables de la vida cotidiana, los premios y castigos como recompensa de ciertas conductas. En suma, en el núcleo de la experiencia escolar se aprehenden e internalizan los criterios de selección, diferenciación y clasificación que operan como filtros de la jerarquía social. De ahí la pertinencia de la pregunta de investigación: ¿en qué consiste la experiencia escolar?

El concepto biografía de experiencia no es un concepto improvisado sino que hunde sus raices en las rupturas y aportes brindados por la sociología comprensiva, la fenomenología y la hermenéutica de la experiencia vivida, en el transcurso de la primera mitad del siglo XX, e incluso desde tiempo atrás, en el arte y la literatura modernas. Es más, entendemos el sustantivo "biografización" en la proximidad de sentido de un proceso de configuración narrativa a la manera de Marcel Proust, quien decía no querer lectores que buscaran entre líneas los secretos de la biografía del autor de En busca del tiempo perdido sino encontrar lectores que fueran lectores de sí mismos, lectores que confrontaran la obra de un tal autor Proust por medio de una lectura de sí mismos.

Por otro lado, el concepto heterobiografia designa tanto el registro de las huellas de la experiencia vivida, como las mediaciones en la comprensión simultánea de los relatos de experiencia de otros y de las escrituras de sí. La heterobiografía se manifiesta en el tornamiento que facilita la inmersión en otras identidades, ya no simplemente en la identificación con una trama $u$ otros personajes de una obra determinada, sino que nos hacemos partícipes de una heterobiografia justo cuando se produce el guiño que aproxima a la comprensión de las experiencias de otros.

La significación de los saberes de experiencia en educación se expresa de diversas formas con presencia en diferentes niveles -ya fue mencionada atrás la relación entre el maestro y el aprendiz, como también los saberes acumulados en la vida social o familiar-, en tanto no deja de constituir una cuestión recurrente en la pedagogía la de cómo acercar los conocimientos escolares y los conocimientos extraescolares. Este es el caso en particular de la educación de adultos que toma como axioma la condición determinante que ejercen las huellas de la experiencia escolar en el proceso de formación de los sujetos.

Dada la naturaleza y función de la escuela, esta representa un microcosmos de aleaciones de saberes, saberes ancestrales o mitopoiéticos o prácticos, donde tiene lugar el intercambio de saberes académicos y redes de símbolos que potencia de forma incesante dicha mezcla, abierto a otros horizontes de formación dife- 
rentes al modelo tradicional de enseñanza de una sola dirección, la del maestro que habla frente a un grupo receptor pasivo. Se generan así otros modelos interesados en el asunto de cómo incorporar siempre saberes extraescolares, el saber de la gente, el relato de experiencias de vida, como condición de posibilidad en los trayectos de "aprendizaje biográfico".

Alheit y Dausien postulan el aprendizaje biográfico como aquel que identifica los acontecimientos decisivos en un horizonte de historia de vida, al tiempo de construir el relato de dichos episodios como la memoria de un sujeto que no acaba de formarse. Los resultados esperados en la aplicación de una estrategia semejante permiten contribuir a cerrar la brecha existente entre las historias de vida de las personas y las expectativas escolares, vistos no solo a través del reconocimiento obvio de que a la escuela asisten seres humanos, no cifras o indicadores de la ecuación costo/beneficio, sino también en el hecho de que esos seres humanos tienen historias que contar, las cuales deben ser escuchadas como premisas en la generación de políticas públicas y otras formas de conocer y hacer.

\section{Nuevas perspectivas sobre la cultura escolar}

Con base en los presupuestos teóricos anteriores, es posible establecer relaciones entre las biografias de la experiencia escolar, el perfil profesional de los maestros y la cultura escolar. A partir de ahí situamos la acción pedagógica en tiempos de incertidumbre, cruzada por una serie de antinomias que se traducen en dilemas característicos en los maestros a la hora de tomar decisiones en situaciones generalmente imprevistas, en ningún caso ajenas a las demandas derivadas de la interacción con distintos actores en la vida cotidiana, ni a las metas y condiciones impuestas por la orga- nización a la que pertenece (HELSPER, 2008). Según este autor, de hecho las antinomias son constitutivas del actuar pedagógico, como una consecuencia del proceso histórico de modernización social y cultural que ha conducido a la ampliación del acceso a las instituciones educativas y, tras ella, a la reacomodación de las metas, objetivos y exigencias de preparación en el oficio de enseñar, como también de las virtudes de la improvisación.

Una primera antinomia enfrenta, por un lado, la lógica de las interacciones de los sujetos que rebasan naturalmente las restricciones impuestas por las reglamentaciones formales y, por otro, las exigencias de la organización regida por principios de racionalidad, eficacia y economía. La burocratización, que es hija natural de la racionalidad moderna, lleva a un punto de tensión entre las escuelas entendidas como dependencias de un sistema orientado con arreglo a fines de calidad, altos estándares, rendimiento, niveles mínimos de deserción, y las instituciones expuestas a las transformaciones dadas las relaciones de fuerza derivadas de las posiciones cambiantes de los participantes y de sus proyecciones subjetivas.

Dichas tensiones que se instalan entre los intereses de la organización como sistema y la pluralidad de intereses individuales que concurren en su interior, inciden sin pausa en la dinámica de las relaciones jerárquicas de poder que no dejan de reflejarse en el espacio social. Son tensiones referidas a lo que Schütze denomina curvas en el curso vital o incidentes críticos, en alusión a los acontecimientos y sucesos que sobrepasan la voluntad o el deseo mismo de los individuos, o rupturas que dejan al descubierto la esencial fragilidad humana. Estos nombran aquellos momentos que superan el monótono transcurrir de la rutina de todos los días, trayendo consigo una sobrecarga de orden cognitivo y emocional, que 
retan al individuo a enfrentar las situaciones inesperadas, como decir, por ejemplo, la pérdida intempestiva del empleo o un ascenso, la irrupción de enfermedades graves o la cura, un duelo o un nacimiento, accidentes o muertes cercanas, la derrota o el triunfo, todos los cuales obligan a un redireccionamiento de la propia existencia.

Basta con citar el caso recurrente de las situaciones extremas que han de afrontar los maestros rurales en nuestro país en medio de los enfrentamientos armados, expresado aquí por Sandra Milena, maestra de Urrao:

La misma guerra me lleva a un nuevo lugar, la muerte de mi hermano en manos de la guerrilla cerca de mi lugar de trabajo, solo por ser un exmilitar y aun conservar físicamente rasgos de militares, y el no saber de mi otro hermano desaparecido por los paramilitares, el acoso en el que vivía por parte de los hombres armados integrantes de los grupos subversivos que me veían con deseo, hizo que mi salud desmejorara, y dio paso a que por fin, los jefes y la JUME (Junta Municipal de Educación, que antes actuaba y cumplía con sus funciones) tomaran la decisión de cambiarme de zona y trasladarme a la escuela rural El Chuscal, donde la violencia no era tan marcada (SEDUCA, 2018, s. p.).

Igualmente, habria que hacer referencia a las circunstancias y modos en que la vida de las instituciones afecta los transcursos vitales de las personas. Por supuesto, además de la familia, la escuela y los entornos laborales imponen también ciertos patrones institucionales que inciden en el transcurso de una historia de vida, incluso en los gestos o acciones minúsculas del acontecer diario, como la disciplina laboral, un régimen horario, el orden o distribución de tareas, los protocolos de relación.

En la cultura escolar, específicamente, existe un amplio espectro de reglas de interacción y comunicación, de rutinas y rituales que median las acciones concretas de los participan- tes, aunque no necesariamente sean explícitas de modo discursivo, todo lo cual constituye precisamente el llamado currículo oculto (JACKSON, 1999, 2002; MCLAREN, 1995). Un botón de muestra del acuerdo negociado con los alumnos acerca del manejo de tiempo de clase, por fuera de las prescripciones instituidas, es expresado así por la maestra Ana María de Urrao:

Mis clases eran monólogos donde les contaba mi vida y les traía historias reales de jóvenes que cómo ellos se atrevían a cambiar el mundo. Básicamente aprendimos a negociar el tiempo de clase, donde yo hablaba casi veinte minutos y ellos trabajaban el resto, a veces, debo confesar que yo hablaba más de los veinte minutos, pero lograba esa conexión desde el alma, me humanizaba frente a ellos, las notas y los contenidos podían esperar, porque lo que nos estaba pasando enfrente era la vida, y eso sí no podía tener espera (SEDUCA, 2018, s. p.).

Sin embargo, incluso a pesar de la multiplicación de esfuerzos de variada índole por romper la estructura vertical y autoritaria de la organización escolar tradicional, no desaparece la tensión vigente entre una praxis educativa casuística, situada y concreta, más adecuada al juego de interacciones en la vida escolar, y una praxis fundada en criterios de estandarización de contenidos, indicadores de logros, eficiencia y control de calidad, importados de la organización industrial. En defensa de la segunda se argumenta acerca de una garantía de estabilidad como condición previa a la acción pedagógica, aunque el precio por pagar esté representado en un orden regulado y de planeación al detalle que pretende excluir la imprevisibilidad, la incertidumbre, la espontaneidad, que son atributos inherentes a la relación de enseñanza-aprendizaje.

En el contexto del actuar pedagógico cotidiano dicha tensión se concreta en la antinomia de una orientación hacia un proceso formativo individual, o bien a la orientación hacia el cumplimiento de tareas de control y 
selección. A este respecto es difícil hallar una defensa más elocuente sobre los principios pedagógicos que deben inspirar el acto de evaluar a un alumno con dificultades, como el siguiente relato de César Martínez, maestro rural en zona Penderisco de Urrao, suroeste de Antioquia:

El niño escapa a la literatura de los grandes pedagogos; es dificil de rotular en los perfiles o estándares convencionales. Darío del Campo es mucho más que un nombre en el diario de campo. La única forma de acompañar el proceso del niño es dejando de lado rótulos, paradigmas, que cosifican la educación llevándola a cuantificar en un afán de medir lo aprendido y que deja de lado al sujeto. La psicometría y la estandarización del conocimiento cada día colonizan más espacios, medir a los niños nos lleva al otro lado de la moneda, es medir al docente. ¿Cómo medir la educación? Esta pregunta nos tendrá siempre enfrentados entre sí, sin aportar mucho al proceso, más allá de la vanidad de quienes enfoquen todas sus energías en un puntaje.

Una segunda antinomia se expresa en términos de cercanía y distancia, por medio de la cual designa, bien sea la proximidad de una relación simétrica o reveladora de una "posición paternal, familiar e intimista", o bien la distancia fundada en la asimetría que diferencia la autoridad del profesor de la posición subalterna del alumno (HELSPER, 1998, p. 206). En los recuerdos de la maestra Sandra Milena, el desfase se convierte en la amenaza de un probable fracaso escolar:

"Así lo viví aquel día en el que al subir la voz, haciendo el gesto de que algo era sencillo, casi que obvio. Mateo, un niño al que le tomó tiempo aprender a hablar, a leer y a escribir, me mira aterrado, con unos ojos llenos de miedo y me dice: "pero usted no entiende que a usted le parece fácil porque lo sabe, pues a mí me parece dificil porque no lo sé" [...] Si quería hacer una escuela diferente, tenía que empezar por hacer una escuela en la que aprender no produjera miedo, sino asombro.
La tercera antinomia pasa por contraponer un modelo pedagógico basado en un trabajo individualizado o de atención personalizada, a uno que se apoya en la diversificación y, con ella, en la inaplazable misión de educar en y para la diversidad como un signo de nuestros tiempos. Para decirlo en pocas palabras, la escuela es también un escenario de confrontación de tendencias que buscan formar en la pluralidad o en la individualidad.

En este orden de ideas, se concibe la práctica pedagógica vinculada a las múltiples formas de existencia, por lo cual hacen parte integrante de su bagaje teórico conceptos fundamentales tales como: inclusión, interculturalidad, etnicidad, diversidad sexual, cultural, política, a la vez que se educa en los principios rectores del aprender a vivir juntos, cifrados en los conceptos básicos de ciudadanía, civilidad, derechos humanos, ética, capital cultural. Allí anida, por consiguiente, la tensión esencial entre una tendencia unificadora y con pretensiones homogeneizadoras, y una tendencia diferenciadora, proclive a la pluralidad de las formas de vida e interpretación del mundo.

En conclusión, una visión perspectivista de la investigación sobre la cultura escolar permite mostrar la dinámica compleja de las escuelas marcadas por conflictos, tensiones en un campo de fuerzas de la interacción social. La cultura escolar no puede dejar de revelar el campo de luchas de los distintos actores que pujan en correspondencia con sus respectivos aprendizajes biográficos, lo que ha sido sorprendentemente relegado a un segundo plano en la investigación educativa. Aquí navegamos, a contracorriente, haciendo eco de los relatos de experiencia de maestros que se debaten a diario en la vida en las aulas, en las comunidades donde ejercen un papel relevante como líderes sociales, y en los escenarios de formación continua, donde 
mantienen la aspiración de convertir el hacer en un decir que se transmite a otros bajo la forma de saber pedagógico.

\section{Referencias}

ALHEIT, Peter; DAUSIEN, Bettina. En el curso de la vida: educación, formación, biograficidad y género. Edición de Francesc J. Hernàndez. Xàtiva: Instituto Paulo Freire CREC, 2007.

ALLIAUD, Andrea. Los artesanos de la enseñanza: acerca de la formación de maestros con oficio. Buenos Aires: Paidós, 2017.

ALLIAUD, Andrea; ANTELO, Estanislao. Los gajes del oficio: enseñanza, pedagogía y formación. Buenos Aires: Aique, 2009.

BAUMAN, Zygmunt. Los retos de la educación en la modernidad líquida. Traducción de Violeta Núñez. Barcelona: Gedisa, 2008.

BECK, Ulrich; BECK-GERNSHEIM, Elisabeth. La individualización: el individualismo institucionalizado y sus consecuencias sociales y políticas. Traducción de Bernardo Moreno. Barcelona: Paidós, 2003.

BECKER, Howard. Los trucos del oficio. Como conducir su investigación en ciencias sociales. Traducción de Teresa Beatriz Arijón. México: Siglo XXI, 2009.

BECKER, Howard. Mozart, el asesinato y los límites del sentido común: cómo construir teoría a partir de casos. Traducción de Azucena Galattini Buenos Aires: Siglo XXI, 2016a.

BECKER, Howard. Cómo fumar marihuana y tener un buen viaje: una mirada sociológica. Traducción de Horacio Pons Buenos Aires: Siglo XXI, 2016b.

BOURDIEU, Pierre; PASSERON, Jean Claude. La reproducción. Elementos para una teoría del sistema de enseñanza. Traducción de J. Melendres y M. Subirats. México: Laia, 1996.

CONNELLY, Michael; CLANDININ, Jean D. Relatos de experiencia e investigación narrativa. En: LARROSA, Jorge et. al. Déjame que te cuente: ensayos sobre narrativa y educación. Barcelona: Laertes, 1995. p. 11-59.
CONTRERAS, José Domingo. De estudiante a profesor. Socialización y aprendizaje en las prácticas de enseñanza. Revista de Educación, Madrid, n. 282, p. 203-221, 1987

DE CERTEAU, Michel. La invención de lo cotidiano. I. Artes de hacer. Traducción de Alejandro Pescador. México: Universidad Iberoamericana; Instituto Tecnológico y de Estudios Superiores de Occidente, 2007.

DELORY-MOMBERGER, Christine. Experiencia y formación: biografización, biograficidad y heterobiografía. Revista Mexicana de Investigación Educativa, Consejo Mexicano de Investigaciones Educativas, v. XIX, n. 62, p. 695-710, jul./sep. 2014.

DELORY-MOMBERGER, Christine. Biografía y Educación: figuras del individuo-proyecto. Traducción de Juan Alejandro Fernando Gomes. Buenos Aires: CLACSO; Facultad de Filosofía y Letras Universidad de Buenos Aires, 2009.

DUBET, François. El declive de la institución. Profesiones, sujetos e individuos en la modernidad. Traducción de Luciano Padilla. Barcelona: Gedisa, 2006.

DUBET, François; MARTUCCELLI, Danilo. En la escuela. Sociología de la experiencia escolar. Traducción de Eduardo Gudiño Kieffer. Buenos Aires: Losada, 1998.

EISNER, Elliot. El ojo ilustrado. Indagación cualitativa y mejora de la práctica educativa. Traducción de David Cifuentes y Laura López. Barcelona: Paidós, 1998.

ELBAZ, Freema. Teacher thinking: a study of practical knowledge. London: Croom Helm, 1983.

ELLIOTT, John. La investigación-acción en educación. Traducción de Pablo Manzano. Madrid: Morata, 1990.

FLÓREZ, Rafael. Hacia una pedagogía del conocimiento. Santa Fé de Bogotá: McGraw Hill, 1998.

GIROUX, Henri. Los profesores como intelectuales. Hacia una crítica del aprendizaje. Traducción de Isidro Arias. Barcelona: Paidós; Madrid: M.E.C, 1990.

HARGREAVES, Andy. Profesorado, cultura y posmo- 
dernidad: cambian los tiempos, cambia el professorado. Traducción de Pablo Manzano. Madrid: Morata, 1998.

HARGREAVES, Andy. "Presentism, Individualism, and Conservatism". Curriculum Inquiry, The Ontario Institute for Studies in Education of the University, Toronto, 40: 1, p. 143-154, 2009.

HELSPER, Werner. Schulkulturen - die Schule als symbolische Sinnordnung. Zeitschrift für Pädagogik, 54: 1, S p. 63-80, 2008.

HELSPER, W.; BÖHME, J.; KRAMER, R. T.; LINGKOST, A. Reproduktion und Transformation von Schulkulturen - Zur Reflexion schulkultureller Entwicklungsprozesse anhand exemplarischer Beispiele. In: KEUFFER, J. et. al. (Hrsg.). Entwicklung von Schulkultur. Deutscher Studienverlag, Weinheim, 1998. p. 206225.

JACKSON, Philip. Enseñanzas implícitas. Traducción de Alcira Bixio. Buenos Aires: Amorrortu, 1999.

JACKSON, Philip. Prácticas de la enseñanza. Traducción de Gloria Vitale. Buenos Aires: Amorrortu, 2002.

LORTIE, Dan. Schoolteacher. A sociological study. Chicago: Chicago Press, 1975.

LYOTARD, 1989. La condición posmoderna: informe sobre el saber. Traducción de Mariano Antolín Rato. Madrid: Cátedra, 2000.

MCEWAN, Hunter. Las narrativas en el estudio de la docencia. En: McEWAN, HUNTER; EGAN, Kieran. (Comps.). La narrativa en la enseñanza, el aprendizaje y la investigación. Buenos Aires: Amorrortu, 2005. p. 236-259.

MCLAREN, Peter. La escuela como un performance ritual. Hacia una economía política de los signos y gestos educativos. Traducción de Sebastián Figueroa Rodríguez. México: Siglo XXI, 2005.

MCLAREN, Peter. La vida en las escuelas. Una introducción a la pedagogía crítica en los fundamentos de la educación. Traducción de Susana Guardado del Castro. 4. ed. México: Siglo XXI, 2005.
MURILLO, Gabriel Jaime. Por una microfisica de la cultura escolar. Revista Educación y Pedagogia, Medellín, Universidad de Antioquia, Facultad de Educación, v. 14, n. 32, p. 139-159, ene./abr. 2002.

PÉREZ, Ángel. La cultura escolar en la sociedad neoliberal. Madrid: Morata, 1998.

PÉREZ, Ángel; GIMENO, José. Pensamiento y acción en el profesor: de los estudios sobre la planificación al pensamiento práctico. Infancia y Aprendizaje, n. 42, p. 37-64, 1988.

ROCKWELL, Elsie. El trabajo docente hoy. Nuevas bardas, huellas y veredas. En: ROCKWELL, Elsie. Vivir entre escuelas: relatos y presencias. Antología esencial (compilado por Nicolás Arata; Juan Carlos Escalante; Ana Padawer). Ciudad Autónoma de Buenos Aires: CLACSO, 2018. p. 489-520. Libro digital PDF

SCHÖN, Donald. El profesional reflexivo. Cómo piensan los profesionales cuando actúan. Traducción de José Bayo. Buenos Aires: Paidós, 1982.

STENHOUSE, Lawrence Investigación y desarrollo del curriculum. Traducción de Alfredo Guera Miralles. Madrid: Morata, [1981] 1984.

STENHOUSE, Lawrence. El profesor como tema de investigación y desarrollo. Revista de Educación, Madrid, n. 277, p. 43-53, 1985.

VARIOS AUTORES. Relatos de maestros que escriben la paz. Antioquia 2017. Medellín: Secretaría de Educación para la Cultura de Antioquia, 2018. (en proceso de publicación).

ZEICHNER, Kenneth. Dialéctica de la socialización del profesor. Revista de Educación, Madrid, n. 277, p. 95-123, 1985.

ZEICHNER, Kenneth. El maestro como profesional reflexivo. Cuadernos de Pedagogía, Barcelona, n. 220, p. 44-49, 1993.

Recebido em: 07.05.2018

Aprovado em: 11.08.2018 
Andrés Klaus Runge-Peña é Doutor en Ciência da Educação pela Universidade Livre de Berlin. Pós-doutorado no Programa de Investigación en Ciencias Sociales, Niñez y Juventud (CLACSO). Professor Titular do Mestrado e Doutorado en Educación da Universidad de Antioquia. Professor convidado do Doutorado en Ciencias Sociales, Niñez y Juventud da Universidade de Manizales. Coordenador do Grupo de Investigación sobre Formación y Antropología Pedagógica e Histórica. Pesquisador do GRIFARS-UFRN-CNPq. E-mail: andres.runge@udea.edu.co

Calle 67 \# 53-108, bloque 9, oficina 427, tel. (574) 2198717

Gabriel Jaime Murillo-Arango Doctor en Educación: estudios históricos en educación, didáctica y pedagogía por universidad de Antioquia. Profesor de Facultad de Educación de universidad de Antioquia. Integrante del grupo de investigación sobre Formación de Maestros y Antropología Pedagógica e Histórica. Coordinador del Simposio Internacional de Narrativas en Educación de Medellín (Colombia). Cofundador de International Autobiography Association (IABA), chapter America. Sus principales áreas de interés: Filosofía e historia de la educación, historias de maestros, investigación biográfico-narrativa en educación, pedagogía de la memoria. E-mail: gabriel.murillo@udea.edu.co

Calle 67 \# 53-108, bloque 9, oficina 420, Tel. (574) 2198712 